\title{
Dependence on permanent pacemakers inserted after transcatheter aortic valve implantation: predictive factors in a ten-year retrospective analysis
}

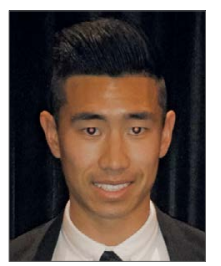

Lance Ng*, MBCHB; Rajesh K. Nair, MBBS, MRCP, FRACP;

Faeez Mohamad Ali, MBBS, MD, MRCP, DM; Sanjeevan Pasupati, MBCHB, FRACP

Waikato Cardiology Department, Waikato Hospital, Waikato District Health Board, Hamilton, New Zealand

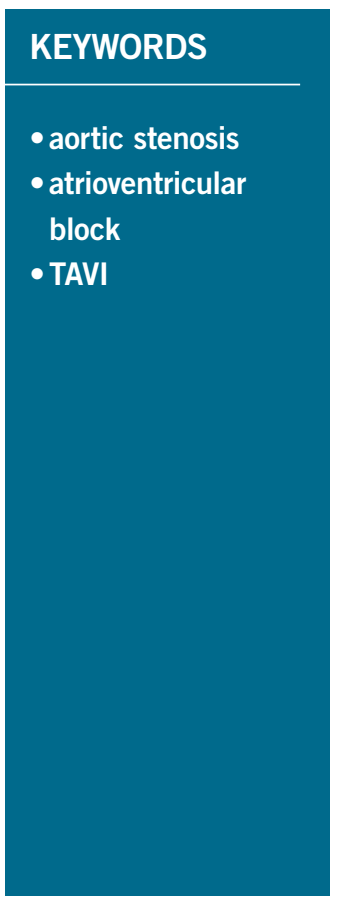

Abstract

Aims: The requirement for a permanent pacemaker (PPM) is an important sequela after transcatheter aortic valve implantation (TAVI). The aim of this analysis was to identify predictive factors for pacemaker dependence in PPM-insertions post-TAVI.

Methods and results: A retrospective analysis of all PPM insertions done between January 2009 and December $2018(\mathrm{n}=1,373)$ identified 33 patients who received a PPM within one month of TAVI. Thirtytwo had completed a PPM check at one year and were included in the final analyses. Of those who had PPM insertions after TAVI, 41\% (13/32) were not PPM-dependent at one year. This cohort was predominantly European (94\%) and over half were octogenerians (56\%). Statistically significant associations with being PPM-dependent at one year include intraoperative PPM dependence (OR 5.714 [95\% CI: 1.16328.070]; $\mathrm{p}=0.032$ ), third-degree heart block being the indication for PPM insertion (OR 8.533 [95\% CI: 1.616-45.063]; $\mathrm{p}=0.012$ ) and mean valve depth over $6.0 \mathrm{~mm}$ (OR 6.222 [95\% CI: 1.200-32.273]; $\mathrm{p}=0.030$ ).

Conclusions: A significant number of patients are not dependent on the PPMs inserted after TAVI. Although small, our study suggests that those who are pacing-dependent intraoperatively, have a thirddegree heart block as their PPM indication or have a mean valve depth of over $6.0 \mathrm{~mm}$, are more likely to be pacing-dependent in the long term. Larger studies are required to draw more definitive conclusions. 


$\begin{array}{ll}\text { Abbreviations } \\ \text { ANZACS-QI } & \text { All New Zealand Acute Coronary Syndrome Quality } \\ & \text { Improvement } \\ \text { AV } & \text { atrioventricular } \\ \text { ECG } & \text { electrocardiogram } \\ \text { ICD } & \text { implantable cardioverter defibrillator } \\ \text { LAFB } & \text { left anterior fascicular block } \\ \text { LVEF } & \text { left ventricular ejection fraction } \\ \text { LVOT } & \text { left ventricular outflow tract } \\ \text { PPM } & \text { permanent pacemaker } \\ \text { RBBB } & \text { right bundle branch block } \\ \text { RV } & \text { right ventricle } \\ \text { RVOT } & \text { right ventricular outflow tract } \\ \text { TAVI } & \text { transcatheter aortic valve implantation }\end{array}$

\section{Introduction}

Permanent pacemaker (PPM) requirement is an important sequela after transcatheter aortic valve implantation (TAVI) as it is associated with increased length of stay, increased cost of care and increased readmission rates ${ }^{1,2}$. There is conflicting evidence regarding the association between post-TAVI PPM requirement and mortality ${ }^{1-4}$. As the indications for TAVI expand to a younger, less comorbid cohort, the ramifications of having an additional device in situ long-term increase.

The aims of this retrospective analysis were to assess PPM dependence at one year and then to assess for any variables which may be predictive of PPM dependence at one year. We sought to assess PPM dependence at one year as a number of studies have suggested that up to half of those with PPMs inserted within 30 days post-TAVI are no longer dependent on their PPM at one year ${ }^{5,6}$. Moreover, gaining a better understanding of the determinants for dependence at one year may help delineate those whose conducting systems are possibly more likely to recover (and not be PPM dependent) and those whose conducting systems are less likely to recover (and be PPM dependent).

\section{Methods}

We used the All New Zealand Acute Coronary Syndrome Quality Improvement (ANZACS-QI) Device Database to identify all PPM insertions performed at Waikato Hospital in the 10-year interval between January 2009 and December 2018.

The ANZACS-QI Device Database is a web-based electronic database which captures a gamut of variables on each device implantation (PPM and implantable cardioverter defibrillators [ICDs]) performed in New Zealand's public hospitals. The specifics regarding data flow and management and data outputs have been previously described ${ }^{7}$.

Of 1,373 patients who had PPM insertions at our institution in the pre-specified ten-year period, 33 had TAVI in the month prior to their PPM insertion. Of those, 32 received a PPM device interrogation at one year and were included in the final analyses. In the same time period, there were 344 TAVIs implanted at our institution.

PPM dependence was defined as having either (i) no escape rhythm when pacing rate lowered to 30 beats per minute, (ii) symptoms before pacing rate lowered to 30 beats per minute or (iii) a rhythm with a class I indication for pacing (for example, complete heart block or second-degree Mobitz II heart block).

Statistical analyses for odds ratios for predictors of PPM dependence were undertaken using Prism 8 (GraphPad Software).

\section{Results \\ BASELINE DEMOGRAPHIC DATA}

The demography in the analysed sample is in keeping with the known demographic profile of those with severe aortic stenosis in New Zealand whereby the incidence per 100,000 is markedly higher in the octogenarian group. This being said, although Ministry of Health data suggests a 2.5:1 incidence of aortic stenosis mortality between non-Maori and Maori, respectively, our cohort is disproportionately non-Maori $(96.9 \%)^{8}$.

\section{BASELINE STRUCTURAL-SPECIFIC PARAMETERS}

From a structural perspective, $68.8 \%$ had a left ventricular ejection fraction (LVEF) greater than $50 \%$ and over two thirds had a left ventricular outflow tract (LVOT) diameter greater than $2.1 \mathrm{~cm}$. CoreValve $^{\circledR}$ (Medtronic, Minneapolis, MN, USA) and Evolut ${ }^{\mathrm{TM}} \mathrm{R}$ (Medtronic) made up almost $70 \%$ (22/32) of the valves implanted. Other valves utilised included: Hydra $(n=1$, Vascular Innovations Co., Nonthaburi, Thailand), Jena $(\mathrm{n}=1$, JenaValve Technology, Munich, Germany), Lotus ${ }^{\mathrm{TM}}$ ( $\mathrm{n}=5$, Boston Scientific, Marlborough, MA, USA), SAPIEN XT ( $n=1$, Edwards Lifesciences Inc., Irvine, CA, USA) and SAPIEN 3 ( $n=2$, Edwards Lifesciences). A valve size of greater than $26 \mathrm{~mm}$ occurred in $68.8 \%$ (22/32) of the sample and recaptures (one or more) were required in $31.3 \%(10 / 32)$. Valve depth was noted at the septal side as well as a mean of the septal and non-septal sides; 68.8\% (22/32) of the cohort had a mean valve implantation depth (defined as [septal side+non-septal side]/2) of at least $6 \mathrm{~mm}$.

\section{BASELINE ELECTROPHYSIOLOGICAL-SPECIFIC PARAMETERS}

From an electrophysiological perspective, almost half were dependent on pacing during the procedure. Complete heart block made up $65.6 \%(21 / 32)$ of the indications for PPM insertion. Baseline electrocardiogram (ECG) abnormalities captured preprocedurally included baseline left anterior fascicular block (40.6\%), baseline first-degree heart block (37.5\%) and baseline right bundle branch block (31.3\%). A total of $40.6 \%(13 / 32)$ were on either AV nodal blocking or anti-arrhythmic medications prior to the procedure. Dual-chamber devices were sited in $71.9 \%$ (23/32) and $21.9 \%$ had ventricular pacing thresholds of greater than $0.7 \mathrm{~V}$. All but five out of $32 \mathrm{RV}$ leads were sited either in the septum or right ventricular outflow tract (RVOT).

\section{ONE-YEAR FOLLOW-UP OUTCOMES}

Of those who had PPM insertions within a month after TAVI, $41 \%$ (13/32) were not PPM dependent at one year.

Of all the structural parameters, a mean valve implantation depth ([septal side+non-septal side]/2) of $6.0 \mathrm{~mm}$ or more had 
a statistically significant association with PPM dependence at one year (OR 6.222 [95\% CI: 1.200-2.273]; p=0.030). Equally there was a trend towards PPM dependence with a valve size of greater than $26 \mathrm{~mm}$, but this did not reach statistical significance (OR 3.214 [95\% CI: 0.682-15.159]; $\mathrm{p}=0.140$ ).
In terms of electrophysiological parameters, intraoperative PPM dependence (OR 5.714 [95\% CI: 1.163-28.070]; p=0.032) and complete heart block as indication for PPM (OR 8.533 [95\% CI: 1.616-45.063]; $\mathrm{p}=0.012$ ) had statistically significant associations with PPM dependence at one year (Table 1).

Table 1. Overall numbers and numbers dependent on permanent pacemaker at one-year stratified by demographic, structural and electrophysiological parameters.

\begin{tabular}{|c|c|c|c|c|c|}
\hline Characteristic & Overall sample & $\begin{array}{l}\text { PPM dependent } \\
\text { at } 1 \text { year }\end{array}$ & $\begin{array}{l}\text { Not PPM dependent } \\
\text { at } 1 \text { year }\end{array}$ & $\begin{array}{l}\text { Odds ratio } \\
(95 \% \mathrm{CI})\end{array}$ & $p$-value \\
\hline \multicolumn{6}{|l|}{ Demographic } \\
\hline \multirow[t]{2}{*}{ Age } & $<80$ & 14 & 10 & 4 & \multirow{2}{*}{$\begin{array}{l}\mathrm{OR}=0.400(0.091-1.762) \\
p=0.226\end{array}$} \\
\hline & $>80$ & 18 & 9 & 9 & \\
\hline \multirow[t]{2}{*}{ Gender } & $\mathrm{M}$ & 25 & 17 & 8 & \multirow{2}{*}{$\begin{array}{l}\mathrm{OR}=5.313(0.842-33.539) \\
p=0.076\end{array}$} \\
\hline & $\mathrm{F}$ & 7 & 2 & 5 & \\
\hline \multirow[t]{3}{*}{ Ethnicity } & European & 30 & 19 & 11 & \multirow{3}{*}{$\begin{array}{l}\mathrm{OR}=8.478(0.373-192.510) \\
p=0.180\end{array}$} \\
\hline & Maori & 1 & 0 & 1 & \\
\hline & Other & 1 & 0 & 1 & \\
\hline \multicolumn{6}{|l|}{ Structural parameters } \\
\hline \multirow[t]{2}{*}{ LVEF } & $\leq 50 \%$ & 10 & 6 & 4 & \multirow{2}{*}{$\begin{array}{l}\text { OR=1.039 }(0.226-4.769) \\
p=0.961\end{array}$} \\
\hline & $>50 \%$ & 22 & 13 & 9 & \\
\hline \multirow[t]{2}{*}{ LVOT } & $\leq 2.1 \mathrm{~cm}$ & 10 & 6 & 4 & \multirow{2}{*}{$\begin{array}{l}\text { OR=1.039 (0.226-4.769) } \\
p=0.961\end{array}$} \\
\hline & $>2.1 \mathrm{~cm}$ & 22 & 13 & 9 & \\
\hline \multirow[t]{2}{*}{ Valve type } & CoreValve/Evolut R & 22 & 13 & 9 & \multirow{2}{*}{$\begin{array}{l}\text { OR=0.963 (0.210-4.421) } \\
p=0.961\end{array}$} \\
\hline & Other & 10 & 6 & 4 & \\
\hline \multirow[t]{2}{*}{ Valve size } & $\leq 26 \mathrm{~mm}$ & 10 & 4 & 6 & \multirow{2}{*}{$\begin{array}{l}\mathrm{OR}=3.214(0.682-15.159) \\
p=0.140\end{array}$} \\
\hline & $>26 \mathrm{~mm}$ & 22 & 15 & 7 & \\
\hline \multirow[t]{2}{*}{ Recaptures } & Any & 10 & 7 & 3 & \multirow{2}{*}{$\begin{array}{l}\mathrm{OR}=1.944(0.396-9.552) \\
p=0.413\end{array}$} \\
\hline & None & 22 & 12 & 10 & \\
\hline \multirow[t]{2}{*}{ Valve depth (septal) } & $\geq 6.0 \mathrm{~mm}$ & 19 & 13 & 6 & \multirow{2}{*}{$\begin{array}{l}\mathrm{OR}=2.528(0.588-10.859) \\
p=0.212\end{array}$} \\
\hline & $<6.0 \mathrm{~mm}$ & 13 & 6 & 7 & \\
\hline \multirow{2}{*}{$\begin{array}{l}\text { Valve depth mean } \\
\text { ([Septal + non-septal]/2) }\end{array}$} & $\geq 6.0 \mathrm{~mm}$ & 22 & 16 & 6 & \multirow{2}{*}{$\begin{array}{l}\text { OR=6.222 }(1.200-32.273) \\
p=0.030\end{array}$} \\
\hline & $<6.0 \mathrm{~mm}$ & 10 & 3 & 7 & \\
\hline \multicolumn{6}{|c|}{ Electrophysiological parameters } \\
\hline \multirow{2}{*}{$\begin{array}{l}\text { Intraoperative PPM } \\
\text { Dependence }\end{array}$} & Yes & 15 & 12 & 3 & \multirow{2}{*}{$\begin{array}{l}\text { OR=5.714 (1.163-28.070) } \\
p=0.032\end{array}$} \\
\hline & No & 17 & 7 & 10 & \\
\hline Arrhythmia Indicating & Third-degree heart block & 21 & 16 & 5 & $\mathrm{OR}=8.533(1.616-45.063)$ \\
\hline PPM & Other (Mobitz II/pauses) & 11 & 3 & 8 & $p=0.012$ \\
\hline Baseline LAFB & Yes & 13 & 10 & 3 & OR=3.704 (0.768-17.864) \\
\hline & No & 19 & 9 & 10 & $p=0.103$ \\
\hline Baseline $1^{\text {st }}$ degree AV & Yes & 12 & 7 & 5 & $\mathrm{OR}=0.933(0.218-4.000)$ \\
\hline block & No & 20 & 12 & 8 & $p=0.926$ \\
\hline Baseline RBBB & Yes & 10 & 8 & 2 & $\mathrm{OR}=4.000(0.688-23.262)$ \\
\hline & No & 22 & 11 & 11 & $p=0.123$ \\
\hline Rate limiting/anti- & Yes & 13 & 9 & 4 & $\mathrm{OR}=2.025(0.460-8.919)$ \\
\hline arrhythmic drugs & No & 19 & 10 & 6 & $p=0.351$ \\
\hline Device type & Single chamber & 9 & 6 & 3 & OR=1.539 (0.307-7.717) \\
\hline & Dual chamber & 23 & 13 & 10 & $p=0.601$ \\
\hline Pacing threshold (V-lead) & $>0.7$ & 7 & 3 & 4 & $\mathrm{OR}=0.419(0.077-2.321)$ \\
\hline & $\leq 0.7$ & 25 & 16 & 9 & $p=0.321$ \\
\hline Site of RV lead & Septum/RVOT & 27 & 18 & 9 & $\mathrm{OR}=8.000(0.776-82.460)$ \\
\hline & Apex & 5 & 1 & 4 & $p=0.081$ \\
\hline
\end{tabular}




\section{Discussion}

Our retrospective analysis of a ten-year period of PPM insertions post-TAVI has uncovered a number of valuable findings.

In terms of one-year follow-up outcomes, our rate of PPM dependence at one year of $59 \%$ echoes the rates observed in larger registry datasets, where up to $50 \%$ of those with a PPM inserted within one month after TAVI are no longer PPM dependent ${ }^{5,6}$. The consistency of this finding across registries would suggest that there may be an element of reversible, acute conduction system blockade which then improves gradually over time. This temporary insult may well be either ischaemic (in cases of coronary artery ostial occlusion) or mechanical ${ }^{9}$.

Indeed, the possibility of a predominantly mechanical mode of injury to the conducting system is supported by our finding of mean valve implantation depth being statistically significantly associated with PPM dependence at one year. Although implantation depth can be underestimated, as there is variability depending on the radiographic projection at the time of the aortogram, it provides a realtime, practical solution for the operators to guide discharge planning. Anatomically, the proximity of the left bundle branch of the His bundle to the right and non-coronary cusps makes the notion of a more deeply implanted valve causing impingement of the conducting system entirely plausible (either directly or by local myocardial oedema $)^{10}$. Our finding is supported elsewhere in the literature-where not only valve implantation depth but also length of the membranous septum have been noted as predictors for high-degree AV block and need for PPM ${ }^{10-12}$. Specifically, there is also literature to support the use of mean valve implantation depth rather than depth at any specific coronary cusp as a potential predictor for PPM requirement ${ }^{13}$.

The analysis of our electrophysiological parameters highlighted the significance of the intraoperative PPM requirement and the presence of complete heart block as predictors of PPM dependence at one year. These findings may suggest that the presence of a higher degree blockade (manifested by requiring a PPM intraoperatively or developing $\mathrm{CHB}$ ) rather than a more temporary AV node level lesion (for example, represented by a transient seconddegree AV block) is a key driver for PPM dependence long term ${ }^{14}$. This being said, it remains difficult to ascertain whether a postTAVI conduction disturbance will persist or self-resolve. In 2017, Tovia-Brodie et al attempted to find further predictors for PPM requirement with electrophysiology studies but were only able to garner similar findings to our study, whereby intraprocedural complete AV block and post-procedure high-grade AV block remained the only clear predictors. Use of electrophysiology studies (EPS) and, specifically, use of serial measurements of the His-Ventricular (HV) interval have yielded mixed results in terms of predicting the need for PPM in a number of small studies ${ }^{15-17}$.

\section{Limitations}

The limitations of our analysis include the limited sample size over the pre-specified ten-year period analysed as well as the definition and nature of PPM dependence. It is recognised that PPM dependence can be a variable phenomenon which fluctuates over time ${ }^{6}$. As such, a patient may well have significant conducting system disease which is not captured by our analysis as they do not appear to meet any of the criteria for dependence at the time of device interrogation. One could go on to speculate that the phenomenon of unexplained sudden deaths after TAVI may represent those with intermittent conducting system disease who are not recognised in the immediate post-operative phase. In addition, we recognise that using an endpoint of PPM dependence does not necessarily correlate to whether a PPM was appropriate for the same reasons noted above regarding the intermittent nature of PPM dependence. Indeed, the PPM which prevents our typically older and more comorbid TAVI patients from having a bradyarrhythmia-induced fall would be completely justified.

Future directions may include forms of electrophysiological testing beyond assessments of the HV interval, such as using rapid atrial pacing to detect Wenckebach physiology in the AV node, as this may serve as a predictor for PPM requirement as suggested by the work done by Krishnaswamy et al $(2020)^{18}$. Equally, the use of implantable loop recorders after TAVI in selected higher-risk patients has shown promise in identifying those with post-TAVI late-onset conduction disturbances ${ }^{19}$. Furthermore, given the significant rates of those who do not appear to be PPM dependent at one year, consideration could be given to the use of pacing devices which could be implanted semi-permanently and then removed at a later point once it is clear that the conduction system has completely recovered.

In addition, as experience grows and valve technologies adapt, refinements in valve implantation depth as well recognition of key risk factors will continue to play a part in reducing rates of post-TAVI PPM requirement. Just as industry and clinicians have moved to reduce rates of paravalvular leak, the next frontier in improving TAVI outcomes will undoubtedly turn the focus onto post-procedural PPM requirement.

\section{Conclusions}

In keeping with other larger registry datasets, $41 \%$ of our cohort were not PPM dependent at one year. In this small retrospective analysis, mean valve implantation depth, PPM dependence during TAVI and complete heart block as indication for PPM insertion were predictors of PPM dependence at one year - all those PPM-dependent at one year in this cohort had at least one of these predictors. Larger studies with collaboration between structural and electrophysiology subspecialties are required to glean further insights into and improve rates of post-TAVI PPM requirement and dependence in order to continue to allow TAVI to evolve as a safe and reproducible intervention for aortic stenosis.

\section{Impact on daily practice}

The findings from this 10 -year, single-centre, retrospective analysis will help clinicians identify patients who are not only at highest risk for requiring post-TAVI pacemaker insertion but also those who are most likely to be dependent in the long term on their pacemaker. Ultimately, this can help TAVI operators risk stratify patients based on measurable structural and electrophysiological parameters. 


\section{Conflict of interest statement}

The authors have no conflicts of interest to declare.

\section{References}

1. Chamandi C, Barbanti M, Munoz-Garcia A, Latib A, NombelaFranco L, Gutiérrez-Ibanez E, Veiga-Fernandez G, Cheema A, CruzGonzalez I, Serra V, Tamburino C, Mangieri A, Colombo A, Jimenez-Quevedo P, Elizaga J, Laughlin G, Lee D, Del Blanco B, Rodriguez-Gabella T, Marsal J, Côté M, Philippon F, Rodés-Cabau J. Long-term Outcomes in Patients With New Permanent Pacemaker Implantation Following Transcatheter Aortic Valve Replacement. JACC Cardiovasc Interv. 2018;11:301-10.

2. Fadahunsi OO, Olowoyeye A, Ukaigwe A, Li Z, Vora AN, Vemulapalli S, Elgin E, Donato A. Incidence, Predictors and Outcomes Of Permanent Pacemaker Implantation Following Transcatheter Aortic Valve Replacement: Analysis From the U.S. Society of Thoracic Surgeons/American College of Cardiology TVT Registry. JACC Cardiovasc Interv. 2016;9:2189-99.

3. Urena M, Webb JG, Tamburino C, Munoz-Garcia AJ, Cheema A, Dager AE, Serra V, Amat-Santos IJ, Barbanti M, Imme S, Alonso Briales JH, Miguel Benitez L, Al Lawati H, Cucalon AM, Del Blanco BG, Lopez J, Dumont E, Delarochellière R, Ribeiro HB, Nombela-Franco L, Philippon F, Rodés-Cabau J. Permanent pacemaker implantation after transcatheter aortic valve implantation: impact on late clinical outcomes and left ventricular function. Circulation. 2014;129:1233-43.

4. Nazif TM, Dizon JM, Hahn RT, Xu K, Babaliaros V, Douglas PS, El-Chami MF, Herrmann HC, Mack M, Makkar RR, Miller DC, Pichard A, Tuzcu EM, Szeto WY, Webb JG, Moses JW, Smith CR, Williams MR, Leon MB, Kodali SK; PARTNER Publications Office. Predictors and clinical outcomes of permanent pacemaker implantation after transcatheter aortic valve replacement: the PARTNER (Placement of AoRtic TraNscathetER Valves) Trial and Registry. JACC Cardiovasc Interv. 2015;8:60-9.

5. Regueiro A, Abdul-Jawad Altisent O, Del Trigo M, CampeloParada F, Puri R, Urena M, Philippon F, Rodés-Cabau J. Impact of New-Onset Left Bundle Branch Block and Periprocedural Pacemaker Implantation on Clinical Outcomes in Patients Undergoing Transcatheter Aortic Valve Replacement: A Systematic Review and Meta-Analysis. Circ Cardiovasc Interv. 2016;9:e003635.

6. Meduri CU, Kereiakes DJ, Rajagopal V, Makkar RR, O'Hair D, Linke A, Waksman R, Babliaros V, Stoler RC, Mishkel GJ, Rizik DG, Iyer VS, Schindler J, Allocco DJ, Meredith IT, Feldman TE, Reardon MJ. Pacemaker Implantation and Dependency After Transcatheter Aortic Valve Replacement in the REPRISE III Trial. J Am Heart Assoc. 2019;8:e012594.

7. Foo FS, Lee M, Heaven D, Lever N, Sinclair S, Stiles MK, Harding S, Boddington D, Larsen P, Jackson R, Kerr AJ. Completeness of ANZACS-QI Cardiac Implanted DEVICE Registry and agreement with national datasets: ANZACS-QI 30. N Z Med J. 2019;132:40-9.

8. National Health Committee, Wellington, New Zealand. Aortic Stenosis: Tier 2 Overview. National Health Committee. PO Box 5013, Wellington, New Zealand. https://www.moh.govt.nz > notebook > nbbooks.nsf (last accessed 30/10/2021)

9. Toggweiler S, Kobza R. Pacemaker implantation after transcatheter aortic valve: why is this still happening? J Thorac Dis. 2018;10:S3614-9.
10. Hamdan A, Guetta V, Klempfner R, Konen E, Raanani E, Glikson M, Goitein O, Segev A, Barbash I, Fefer P, Spiegelstein D, Goldenberg I, Schwammenthal E. Inverse Relationship Between Membranous Septal Length and the Risk of Atrioventricular Block in Patients Undergoing Transcatheter Aortic Valve Implantation. JACC Cardiovasc Interv. 2015;8:1218-28.

11. Maeno Y, Abramowitz Y, Kawamori H, Kazuno Y, Kubo S, Takahashi N, Mangat G, Okuyama K, Kashif M, Chakravarty T, Nakamura M, Cheng W, Friedman J, Berman D, Makkar RR, Jilaihawi H. A Highly Predictive Risk Model for Pacemaker Implantation After TAVR. JACC Cardiovasc Imaging. 2017;10: 1139-47.

12. Husser O, Pellegrini C, Kessler T, Burgdorf C, Thaller H, Mayr NP, Kasel AM, Kastrati A, Schunkert H, Hengstenberg C. Predictors Of Permanent Pacemaker Implantations and New-Onset Conduction Abnormalities With the SAPIEN 3 Balloon-Expandable Transcatheter Heart Valve. JACC Cardiovasc Interv. 2016;9: 244-54.

13. Lenders GD, Collas V, Hernandez JM, Legrand V, Danenberg HD, den Heijer P, Rodrigus IE, Paelinck BP, Vrints CJ, Bosmans JM. Depth of valve implantation, conduction disturbances and pacemaker implantation with CoreValve and CoreValve Accutrak system for Transcatheter Aortic Valve Implantation, a multi-center study. Int $J$ Cardiol. 2014;176:771-5.

14. Tovia-Brodie O, Michowitz Y, Belhassen B. Use of Electrophysiological Studies in Transcatheter Aortic Valve Implantation. Arrhythm Eltrophysiol Rev. 2020;9:20-7.

15. Tovia-Brodie O, Ben-Haim Y, Joffe E, Finkelstein A, Glick A, Rosso R, Belhassen B, Michowitz Y. The value of electrophysiologic study in decision-making regarding the need for pacemaker implantation after TAVI. J Interv Car Electrophysiol. 2017;48:121-30.

16. Rogers T, Devraj M, Thomaides A, Steinvil A, Lipinski MJ, Buchanan KD, Alraies MC, Koifman E, Gai J, Torguson R, Okubagzi P, Ben-Dor I, Pichard AD, Satler LF, Waksman R. Utility of Invasive Electrophysiology Studies In Patients With Severe Aortic Stenosis Undergoing Transcatheter Aortic Valve Implantation. Am J Cardiol. 2018;121:1351-7.

17. Makki N, Dollery J, Jones D, Crestanello J, Lily S. Conduction disturbances after TAVR: electrophysiological studies and pacemaker dependency. Cardiovasc Revasc Med. 2017;18:S10-3.

18. Krishnaswamy A, Sammour Y, Mangieri A, Kadri A, Karrthik A, Banerjee K, Kaur M, Giannini F, Pagliaro B, Ancona M, Pagnesi M, Laricchia A, Weisz G, Lyden M, Bazarbashi N, Gad M, Ahuja K, Mich S, Svensson L, Puri R, Reed G, Rickard J, Colombo A, Kapadia S, Latib A. The Utility of Rapid Atrial Pacing Immediately Post-TAVR to Predict the Need for Pacemaker Implantation. JACC Cardiovasc Interv. 2020;13:1046-54.

19. Rodés-Cabau J, Urena M, Nombela-Franco L, Amat-Santos I, Kleiman N, Munoz-Garcia A, Atienza F, Serra V, Deyell MW, VeigaFernandez G, Masson J, Canadas-Godoy V, Himbert D, Castrodeza J, Elizaga J, Pascual JF, Webb JG, de la Torre JM, Asmarats L, PelletierBeaumont E, Philippon F. Arrhythmic Burden as Determined by Ambulatory Continuous Cardiac Monitoring in Patients With NewOnset Persistent Left Bundle Branch Block Following Transcatheter Aortic Valve Replacement: The MARE Study. JACC Cardiovasc Interv. 2018;11:1495-505. 